\title{
A CONSTRUÇÃO DO REAL como papel da cultura
}

\section{Cid Seixas}

O mytho é o nada que é tudo.

Fernando Pessoa

O conceito de realidade não permanece o mesmo em todos os momentos da história do homem nem em todas as culturas e sociedades. Cada cultura, de modo mais ou menos inconsciente, se reserva a tarefa de estabelecer as fronteiras do que entende por real. Objetos do conhecimento, como as coisas abstratas e os fatos concretos, entidades mitológicas, ou divinas, que são incluídas por um povo, ou por um segmento cultural, como pertencentes à esfera da realidade, podem ser tomados por outro segmento como criações e alegorias de uma cultura.

Vergílio Ferreira, romancista voltado para a reflexão filosófica, põe na boca do narrador de Mudança a consciência da descoberta: "Vamos na vida como um automóvel na noite. O que importa, em cada momento é o que é batido dos faróis. Sei o que está até o extremo do facho. Para lá, ignoro.” (Ferreira, 1969, p. 143)

A chamada civilização ocidental cristã inclui na realidade, tomemos por exemplo, a existência da Santíssima Trindade. Para os povos cristãos, a convivência de um Deus em três pessoas, do Pai, do Filho e do Espírito Santo, é tão real quanto a existência dos planetas, dos ventos ou dos fenômenos sísmicos. Trata-se de uma realidade não palpável, não concreta; substância abstrata, portanto; mas de uma realidade, tão plena e poderosa como a realidade material. 
Não obstante, esta mesma civilização não hesita em excluir dos limites do real entidades divinas de outros povos, como Arimã e Osmuz, Tupã e Osíris, Exu e Pomba Gira. Algumas culturas, como a brasileira, através do segmento dominante e oficial, constituído pelo esforço de afastar o substrato negro e índio, são impermeáveis aos valores "bárbaros". Deste modo, divindades como Oxalá, Iemanjá ou Oxóssi são vistas como criações do espírito popular e da superstição inculta.

Contrariamente, para alguns povos africanos, como também para um expressivo segmento cultural da população negromestiça da cidade da Bahia, são os Orixás passageiros clandestinos dos navios negreiros que trocaram as florestas mágicas do continente primeiro pelas árvores sagradas dos terreiros de encantado da antiga capital de Pindorama - que constituem a realidade mais próxima e sensível. As entidades míticas do cristianismo e do judaísmo romanizado são referências prestigiosas do grupo dominante, valores que se impõem como mitos mortos, senhas de acesso ao vértice da pirâmide.

Além das crenças e tradições de cada povo, nada autoriza ao homem a considerar a Pomba do Espírito Santo mais real do que a Pomba Gira, as bruxas ou o Saci Pererê, nem Iansã ou Oxalá mais ou menos verdadeiros do que Santa Bárbara ou Jesus Cristo, filho natural do Deus de Israel.

Assim é que um incerto mestre Caeiro, fingido homem do campo que pôde fugir das teias da civilização, descobriu que

A Virgem Maria leva as tardes da eternidade a fazer meia.

E o Espírito Santo coça-se com o bico

E empoleira-se nas cadeiras e suja-as. (Pessoa, 1972, p. 210)

Como o homem, Narciso no espelho, procura eleger deuses que sejam a sua imagem e semelhança, cada cultura tece os mitos mais convenientes à sua glorificação.

Não é por acaso que se afirma que a realidade é diferente não só de povo para povo, mas de indivíduo para indivíduo. A educação, a história de vida, as crenças e convicções, aliadas ao nível de informação, dirigem a percepção humana para um determinado caminho, privilegiando aspectos que podem passar desapercebidos a uma outra pessoa, submetida a uma situação diferente. Os anseios e desejos do homem não podem ser ignorados como fatos que atuam decisivamente no seu modo de perceber e construir o real, quer sejam nas formas de fantasias individuais ou nas grandes 
fantasias coletivas que ganham o estatuto de realidade, conferido pela sociedade e pela cultura.

A existência de mitos responsáveis pela construção da realidade individual e coletiva levou Claude Lévi-Strauss (1949 e 1955) a forjar a expressão mito individual. Também Jacques Lacan (1965), a partir do trabalho de Lévi-Strauss, escreveu O mito individual do neurótico, onde analisa a estrutura da construção da realidade empreendida por um indivíduo, em oposição à realidade coletivamente compartilhada. As estruturas psíquicas que ocupam a atenção da clínica psicanalítica são fontes criadoras de mitos destinados a assumir no espaço do sujeito o lugar e o efeito dos grandes mitos da tribo ou aldeia global.

Através dos seus sentidos e dos seus órgãos, o animal apreende o mundo que o rodeia. O aperfeiçoamento de um sentido, ou a utilização de vários sentidos, coordenadamente, influencia o modo de apreender, criando a diversidade de vida dos insetos, dos pássaros, dos peixes, dos mamíferos ou dos homens, animais simbólicos que por esta condição se distinguem dos demais.

Ernst Cassirer, na sua Filosofia das formas simbólicas, propõe a modificação do critério que agrupa os animais em racionais e irracionais para simbólicos e não-simbólicos. A capacidade de simbolizar seria responsável pela fundação da cultura, bem como pelo processo acumulativo da experiência registrada pela espécie humana. Se, no primeiro volume, o autor analisa o papel da linguagem como ponto de partida da condição humana, no segundo, destaca o mito como forma de pensamento. Assim é que no mesmo ano de publicação do segundo volume da Filosofia das formas simbólicas aparece o ensaio Linguagem e mito, aproximando ambas as formas de conhecimento.

Assim, a realidade do homem difere da realidade da abelha ou do rato. Enquanto a primeira dispõe de modos de percepção do abstrato e do simbólico, a segunda opera com o concreto e o imediato.

Uma espécie animal que não disponha dos órgãos responsáveis pelo sentido da visão, por exemplo, construirá a realidade de modo diferente de outra que possua este sentido. As relações concretas dos seres com o mundo que os rodeia determinarão não apenas a conduta destes seres como também a sua percepção de si mesmos e do mundo exterior. Isto porque a realidade não se apresenta de forma unitária e homogênea, mas caleidoscopicamente diversificada, possuindo tantos padrões e planos diferentes quantos são diferentes as perspectivas, as espécies e os organismos. Todo organismo, segundo a concepção de Uexkull, é um ser monadário, tem um mundo próprio, porque tem uma experiência própria. Os fenômenos encontrados na vida de certas 
espécies não são transferíveis para nenhuma outra espécie: "As experiências - e portanto as realidades - de dois organismos diferentes são incomensuráveis entre si." (UEXKULL, 1909)

No caso do homem, o progresso científico e tecnológico permite a extensão dos sentidos e a conseqüente modificação da realidade percebida e construída: "projetamos nosso próprio sistema nervoso central num abraço global, abolindo tempo e espaço (pelo menos naquilo que concerne ao nosso planeta). Estamos nos aproximando rapidamente da fase final das extensões do homem: a simulação tecnológica da consciência, pela qual o processo criativo do conhecimento se estenderá coletiva e corporativamente a toda a sociedade humana". (McLuhan, 1964, p. 17)

$\mathrm{Na}$ Idade Média, por exemplo, a noção da realidade era bastante diversa da compartilhada na Idade Mídia. A terra era concebida como uma superfície contínua ao mar, que findava num abismo habitado por monstros gigantescos. Cada século modifica a configuração da realidade, embora se apegue arraigadamente às novas configurações lenta e permanentemente modificadas. Uma vez eleita uma realidade e organizadas as concepções e sentimentos nela baseadas, qualquer alteração na sua estrutura poderá lançar o caos sobre as concepções e sentimentos que constituem o próprio homem.

É com ironia que Fernando Pessoa observa a dificuldade do animal humano de enxergar além das suas próprias projeções. Os velhos fantasmas caseiros falam alto e amarram a memória dos vivos com as mesmas correntes que arrastam pela escuridão da noite. $\mathrm{O}$ processo de construção do real resultante das contingências humanas assusta aos próprios construtores.

Temos agora uma outra Eternidade, E era sempre melhor o que passou. (Pessoa, 1972, p. 139)

Assim, o indivíduo e a cultura se sentem no dever de preservar a configuração estabelecida do real para que não se esfumacem as suas coisas mais gratas, plantadas no terreno desta realidade.

Qualquer mudança na configuração da realidade pode implicar em mudanças no próprio homem e na sociedade, o que é sempre um risco, porque nem o homem nem a sociedade toleram a destruição dos seus valores e convenções, temendo a destruição de si mesmos e a aparição de um novo homem ou de uma nova sociedade.

Galileu pagou seu preço por anunciar ao mundo uma outra concepção das relações dos corpos celestes. A realidade vista pela Inquisição teria seus pilares derruba- 
dos diante das constatações do sábio que propunha, implicitamente, o redimensionamento da realidade estabelecida pelo seu tempo.

O homem procura aquilo que acha - os olhos vêem o que procuram -, inscrevendo o seu trajeto no espaço circular do eterno retorno.

Darwin, com a descoberta das leis da evolução das espécies, foi alvo constante da desconfiança e da indignação dos seus contemporâneos. A revelação de um aspecto até então desconhecido da realidade colocou em crise esta mesma realidade, assentada sobre bases conflitantes com os postulados do cientista. Cada momento da história da cultura é dominado por uma ciência ou por um conjunto de idéias às vezes banidas pelo momento posterior. A Teologia foi a disciplina piloto por muitos anos, sobrevivendo à dialética das idéias desde a Idade Média até o século XIX, em plena modernidade histórica. Assim como a Igreja impôs seu Índex, a pós-modernidade refaz o gesto através das suas instâncias coercitivas, entre as quais se inclui a academia.

O novo assusta porque prenuncia a morte do velho. Todo modo de perceber o mundo que venha a corrigir o aceito tende a ser rejeitado porque oferece o risco de invalidar tudo aquilo que coexiste com o estabelecido. $\mathrm{O}$ homem e a sociedade são verdadeiros edifícios construídos sobre terreno pantanoso - que precisam vigiar a precária argamassa dos seus alicerces.

\section{O FENÔMENO E O OBJETO}

Um fato singular ilustra nosso enfoque do papel da percepção na construção da realidade. Antes de serem inventados os instrumentos capazes de apreender as vibrações sonoras que caracterizam o infra-som e o ultra-som, estas formas da realidade acústica permaneciam à margem da realidade humana. Uma realidade menos abrangente, que encontrava o silêncio onde as vibrações da fonte emissora não atingiam a freqüência de vinte ciclos por segundo, ou iam além de vinte mil ciclos. A presença ostensiva também se converte em ausência perante os sentidos.

Neste ponto, a realidade acústica dos animais capazes de ouvir mais do que o homem é evidentemente mais ampla. Somente com o auxílio de aparelhos o homem ampliaria a sua percepção, através da extensão dos sentidos, para usarmos a expressão de McLuhan.

Pela pertinência temática, convém lembrar o problema suscitado pela aceitação da existência ou da inexistência do som num lugar deserto. Imagine-se a situação de 
uma floresta distante, onde uma árvore cai sem que haja alguém para ouvir o ruído produzido. Há quem afirme que "o som consiste em certos fenômenos físicos que podem produzir-se esteja alguém perto para ouvi-los ou não. O som é um movimento organizado de moléculas que tem origem num corpo que vibra". Outros contra-argumentarão que "o som é uma sensação conhecida apenas pela mente daquele que constata - uma experiência sensorial que podemos relacionar com as nossas vidas materiais e sensitivas". (Guerreiro, 1977, p. 45)

$\mathrm{Na}$ verdade, estamos diante de dois fenômenos diferentes designados pela palavra som, ou reunidos nesta palavra: um fenômeno físico, situado no mundo exterior, e um fenômeno psíquico, situado no interior. A causa, que são as ondas mecânicas viajando na atmosfera e o efeito produzido na consciência pelos impulsos elétricos no ouvido interno.

Mário Guerreiro, na esteira da psicologia fenomenológica, quer demonstrar que o som é um fato da nossa consciência, é aquilo apreendido pelo homem, e não o conjunto de causas materiais; tomando então a autoridade do testemunho de Husserl: "Eu não vejo impressões de cores (farbenentfindungen) mas sim, coisas coloridas; eu não ouço impressões de sons (tonenempfindungen), mas sim a canção". Daí a constatação:

A abordagem fenomenológica recusa este itinerário percorrido a partir dos fatos: coloca-se de imediato no domínio de uma percepção, aceitando aquilo mesmo que nossos ouvidos percebem, sem que necessitem recorrer a qualquer outro ato. De fato, percebemos facilmente as diferenças existentes entre um grito e uma frase articulada, entre o som de uma buzina e o som de um trombone." (Guerreiro, 1977, p. 48)

A discussão do problema é bastante antiga, e já no século XVII Hobbes faz uma síntese das duas interpretações, distinguindo o objeto e a sensação por ele provocada. Ao investir contra as "escolas de Filosofia" que retomam o realismo de Aristóteles, Hobbes esboça uma perspectiva que se aproximaria da fenomenológica. Ele mantém viva a noção de que o homem opera fundamentalmente com aparencias ou representações resultantes das sensações, "pois não há nenhuma concepção no espírito do homem, que primeiro não tenha sido originada, total ou parcialmente, nos órgãos dos sentidos" (Hobbes, 1650, p. 9).

Se no Leviatã o estudo da sensação é tomado como ponto de partida, foi no seu primeiro tratado, Elementos de Lei natural e política, ou $A$ natureza bumana, de 1640, que foram estabelecidas as idéias essenciais de Thomas Hobbes. Aí os sons, as cores, as 
figuras etc. são tomados como sensações, ou seja, como resultantes da natureza humana, e não como fatos existentes no universo físico.

Antes que a tradição científica viesse a falar em fenomenologia, Hobbes fazia uma afirmação possível de ser subscrita por estes filósofos:

Tanto quanto a cor não é inerente ao objeto, mas um efeito dele sobre nós causado por um movimento do objeto tal como foi descrito, assim também o som não está nas coisas que ouvimos mas em nós mesmos. Um sinal manifesto disso é que não só um homem pode ver como também pode ouvir em duplicado, pela multiplicação de ecos, que sendo tantos sons quanto o original, e não estando num único e mesmo lugar, não podem ser inerentes ao corpo que o produziu. Nada pode produzir alguma coisa por si mesmo: o badalo não tem som em si mesmo, mas movimento, e produz movimentos nas partes internas do sino; assim, o sino tem movimento e não som. O movimento do sino comunica movimento ao ar; e o ar tem movimento mas não tem som. O ar comunica movimento ao cérebro, pelo ouvido e nervos; e o cérebro tem movimento mas não tem som. Do cérebro, o movimento repercute-nos nos nervos que regressam ao exterior, e por isso transforma-se numa aparição fora de nós a que chamamos som. (Hobbes, 1640, p. 55)

Concordando ou não com esta descrição, é evidente que o objeto conhecido pelo homem é perpassado pela interferência do sujeito. A realidade não é mais do que a soma estabelecida dos modos de percepção dos indivíduos socialmente organizados. Através de uma espécie de contrato social implícito, os homens submetidos a uma cultura aceitam determinada rede de idéias, crenças concepções e sentimentos que, por serem compartilhadas, estabelecem um forte vínculo entre os seus membros.

Com isso não se pretende negar a existência da realidade natural, nem defender uma compreensão do objeto como construção tipicamente subjetiva. Pretende-se apenas reconhecer o papel ativo do sujeito no processo do conhecimento objetivo.

Dito isto, gostaria de subscrever inteiramente os pontos de vista implícitos na teoria do conhecimento de Adam Schaff e endossar a sua crítica aos materialistas que pretendem desconhecer o papel da subjetividade. Enquanto marxista, Schaff contesta a posição excludente da subjetividade, assumida por alguns dos seus camaradas mais eminentes. Assim, o seu pensamento está distante do de Della Volpe, cuja ortodoxia evoca o materialismo de Feuerbach, contra o qual tanto Marx quanto Engels empreenderam importantes estudos propedêuticos que deram corpo aos dois volumes de $A$ ideologia alemã. 
No artigo crítico "Uma estética marxista: Della Volpe", tive oportunidade de evidenciar a natureza ortodoxa do pensamento dellavolpeano e a sua investida contra outros marxistas, por ele classificados de idealistas, como Lukács, por exemplo. Aí também está presente a discussão em torno da "exorcização dos demônios idealistas" no corpo do marxismo, que seria pitoresca se não estivesse embebida no sangue dos célebres expurgos da vertente prática e totalitária do marxismo.

Nas Teses sobre Feuerbach, Marx diz que

O erro fundamental de todo materialismo passado, incluindo o de Feuerbach, reside em que só capta a coisa («Gengenstand»), a materialidade, o sensível sob a forma de objeto («Objekt») ou de contemplação («Anschanung»), não como atividade humana sensivel, como prática, isto é, também de um modo subjetivo. É por isso que, em oposição ao materialismo, o lado ativo do conhecimento não tem sido desenvolvido senão de um modo abstrato pelo idealismo que, naturalmente, não conhece a atividade real, sensível como tal. Feuerbach aspira a objetos sensíveis, realmente distintos dos objetos conceituais, mas não concebe a própria atividade humana como uma atividade objetiva («Gengenstandliche»)"1.

A citação obedece à tradução constante do livro de Adam Schaff, que coincide com o teor da tradução de Inácio Rangel, feita em 1946, no volume de Marx \& Engels Trechos escolbidos sobre filosofia.

Diverso, no entanto, é o sentido da tradução do filósofo José Arthur Giannotti, onde se lê: "A falha capital de todo materialismo até agora (incluso o de Feuerbach) é captar o objeto, a efetividade, a sensibilidade apenas sob a forma de objeto ou de intuição, e não como atividade humana sensivel, praxis, só de um ponto de vista subjetivo."”

Enquanto nas duas traduções citadas consta que Marx critica Feuerbach por só captar a coisa, a materialidade, o sensível, sob a forma de objeto, deixando de captá-la como atividade humana, como prática, ou seja, de modo subjetivo; na tradução de Giannotti a ambigüidade se instaura na passagem: "e não como atividade bumana sensível, praxis; só de um ponto de vista subjetivo." A expressão "só de um ponto de vista subjetivo" está em flagrante contradição com o restante do período, onde o materialismo tradicional é criticado exatamente por não admitir a subjetividade.

1. Karl Marx: Teses sobre Feuerbach, tese I. In Adam Schaff: Linguagem e conbecimento, p. 7

2 Karl Marx: Teses contra Feuerbach. In: Manuscritos econômico-filosóficos e outros textos escolbidos, p. 51. 
Convém deixar claro que a perspectiva adotada neste nosso texto recusa a distinção que procura opor ideologicamente o subjetivo ao objetivo, por considerá-la sustentável apenas no âmbito do materialismo ortodoxo mais rudimentar, ou do idealismo purista; conforme demonstra a dialética de Schaff.

O materialismo dialético, isto é, aquele que se sustenta no diálogo da subjetividade com a objetividade, da materialidade com a atividade do indivíduo - por isto mesmo chamado de dialético -, permite vislumbrar o caráter objetivo da subjetividade, uma vez que o sujeito é o resultado das relações sociais às quais está submetido.

Em outras palavras: o social é objetivo, assim como o puramente individual é subjetivo. Mas não existe o puramente individual porque o indivíduo é condicionado pela sociedade sobre a qual atua, recebendo de volta a influência de outros indivíduos ao longo do tempo e do espaço, isto é, da história. Como também o social não é puramente objetivo, porque uma sociedade não se constitui de máquinas, mas de homens, que asseguram o caráter flutuante, inexato e rebelde às leis das ciências da natureza, caráter este, ostentado pelas ciências da cultura.

A linguagem, que é um fato social e humano por excelência, apresenta uma estrutura exemplarmente dialética, fazendo pesar sobre os que ingressam no mundo dos homens, ao ingressarem nos seus sistemas simbólicos, o constante confronto com o outro, que é objeto, e o constitui enquanto sujeito.

Veja-se, a propósito, uma passagem das Confissões, de Santo Agostinho, que diz: "por esse processo retinha pouco a pouco as palavras convenientemente dispostas em várias frases e freqüentemente ouvidas como sinais de objetos. Domando a boca segundo aqueles sinais, exprimia por eles as minhas vontades. Assim principiei a comunicar com as pessoas que me rodeavam, e entrei mais profundamente na sociedade tempestuosa dos homens". (Agostinho, 1980, p. 16)

Pensadores de momentos e tendências diversas se encontram num lugar comum: "O homem fala então, mas é porque o símbolo o fez homem" (Lacan, 1978, p.141). Estas palavras de Jacques Lacan repetem a descoberta que remonta a Santo Agostinho e ganha contornos evidentemente sociais em Marx: o homem se faz homem, na acepção que hoje temos, ao partilhar do contrato social, o que se torna possível através do simbólico materializado na linguagem.

Não é por acaso que Rousseau, nos Princípios de direito político, afirma que "a mais antiga de todas as sociedades, e a única natural, é a da família; ainda assim só se prendem os filhos ao pai enquanto dele necessitam para a própria conservação. Desde que tal necessidade cessa, desfaz-se o liame natural”. (Rousseau, 1962a, p. 20) Assim, 
o filósofo procura o elemento capaz de manter os homens unidos através do contrato social.

Fruto das paixões e, basicamente, da necessidade, surge a linguagem articulada para permitir que os homens não se dispersem, "sendo a palavra a primeira instituição social" (Rousseau, 1962b, p. 429). Se, no Contrato social, Rousseau identifica a família como a primeira forma de associação dos homens, uma forma natural, portanto; no Ensaio sobre a origem das linguas, a linguagem aparece como a primeira instituição social. A língua, lugar de encontro do subjetivo com o objetivo, é também a ponte do natural para o cultural.

Tudo isso serve para reforçar a tese segundo a qual o subjetivo é também objetivo; e, por outro lado, como a sociedade é formada por indivíduos, o objetivo é ao mesmo tempo, subjetivo. Considerando o homem como produto das relações sociais às quais está submetido - $e$ das quais é o construtor -, não podemos falar da subjetividade como negação da objetividade, nem vice-versa. Elas são complementaridades. Como observa Schaff, o problema do fator subjetivo adquire outra dimensão quando é encarado do ponto de vista do papel ativo da linguagem no conhecimento.

El problema del factor subjetivo se presenta en otros términos cuando se lo encara desde el punto de vista del papel activo del lenguaje en el conocimiento. (...) Así, por intermedio del lenguaje, el conocimiento está constantemente sometido a la acción de condicionamientos sociales que somos incapaces de superar" (Schaff, 1976, p. 78).

Do mesmo modo que existe uma realidade natural puramente objetiva, porque anterior à instituição da sociedade humana e à construção da cultura, existe também uma outra, dialética, confronto do natural com as imposições do sujeito e da história: resultado da percepção e objeto do conhecimento.

É a isto que chamo de realidade, compreendida não como uma entidade imutável, mas como um processo que reflete a atuação e o pensamento do homem. A outra "realidade", chamada de natural, não contaminada pelo processo histórico e cultural do homem, e independente das formas de conhecimento, não se constitui objeto das ciências da cultura. Daí ser escrita entre aspas, como recurso de delimitação do nosso objeto de estudo.

Aqui, temos em mira a realidade simbólica; das línguas históricas; ou das línguas estéticas: o discurso da arte. 


\section{PASSAGEM DO NATURAL AO SIMBÓLICO}

Podemos diferenciar os modos de construção da realidade pelos animais, em geral, e pelo homem, em particular. Se os primeiros, desprovidos de capacidade de pensar abstratamente, ou da razão e da consciência, estabelecem relações diretas e imediatas com os outros e a natureza, o homem se distancia cada vez mais deste modo ancestral de relações objetivas, mantendo um contato mediato com o mundo, através de um singular instrumento social de conhecimento dos fenômenos que o cercam e de comunicação com os outros homens. A linguagem é o mediador entre o homem e o mundo; o universo simbólico no qual a natureza, a sociedade e o indivíduo se encontram - unificados pelo vínculo cognitivo e comunicativo.

A linguagem é aqui entendida não só como a língua histórica falada por um determinado povo, ou por um conjunto de povos unidos por vínculos comuns ao longo da sua história. Deve-se tomar por linguagem todos os processos simbólicos, representações, gestos, sons, figuras e demais sistemas significativos instituídos no seio de uma cultura - com a dupla finalidade de captar (ou compreender) e transmitir a forma e os limites desta compreensão. Todo este processo implica numa construção - simbólica; humana, portanto.

Enquanto os animais convivem diretamente com os outros e com a natureza, o homem interpõe os processos simbólicos ou os signos como forma de conhecimento e representação de todas as coisas presentes e ausentes. Deste modo, pode trazer para diante de si e dos seus pares no convívio social, pessoas e objetos distantes, ou até mesmo inexistentes, configurados no universo sígnico da linguagem.

Por esta via, o homem articula a ausência e é inserido na sua ordem, a ordem simbólica da linguagem, isto é: da cultura. Ao construir o seu mundo, o homem toma como ponto balizador da objetividade aquilo que é dito pelo outro sujeito; e desta ausência, que é a marca distintiva da realidade humana, nasce o outro.

Umberto Eco, em $A$ estrutura ausente, dedica algumas páginas a Lacan e à lógica do outro, traduzindo a parábola dos três prisioneiros com o exemplo do "par ou impar", onde cada um dos jogadores, ao dar seus palpites, imagina o que o outro imagina o que se imagina dele; para somente dizer "par" se estiver seguro de que ele espera "impar", e vice-versa. "No momento em que jogo imaginando o que ele imaginará que eu imagine, estamos ambos dentro de uma lógica que nos supera: o Outro". (Eco, 1968, p. 324-343) Tal raciocínio nos ajuda a ver mais claramente o momento de 
interposição do Outro, fruto da gregariedade que assegura a natureza social do homem.

Neste sentido, a realidade humana é mais ampla e abrangente do que a dos animais, pois é a unificação do tempo e do espaço, do ontem, do hoje e do amanhã, das terras de aquém e além limites do olhar. $\mathrm{O}$ animal simbólico em que se constitui o animal humano não mais vive preso às fronteiras do universo físico, mas reserva para si e para as gerações futuras o sem-fim do universo simbólico.

A linguagem, através da qual as sociedades e culturas se unificam e constituem, é um mútuo perscrutar-se entre o sujeito e os objetos, sendo ao mesmo tempo uma barreira e uma lente que permite ampliar a percepção. Ou uma lente que, ao ampliar, refrata. Se o homem, com relação aos outros animais, abandona a natureza e passa a viver com os signos, seu conhecimento dos "objetos naturais" passa também a ser marcado pela parcialidade da perspectiva; e sua percepção destes objetos a ser condicionada pelo instrumento mediador.

Podemos tentar um paralelo dizendo que a percepção animal se dá através dos cinco sentidos, enquanto a do homem depende ainda de uma espécie de sentido cultural, que é a sua referência maior: o simbólico. Tal afirmação pode tomar como ponto de partida o papel atribuído à linguagem por Freud. Já em 1895, no Projeto para uma psicologia científica, ele afirma que o conhecimento humano é sempre um processo de reconhecimento.

Arrisco a inferência de que é um processo tríplice e que, antes do conhecimento imediato (re-conhecimento), deve se dar o conhecimento mediato, por meio da linguagem. É tríplice porque, inicialmente, viria a percepção primária: do mundo exterior; em seguida, se desenvolveria um processo de pensamento, através do qual as impressões externas deixariam marcas na memória para finalmente, quando o objeto do mundo externo que provocou a percepção voltar a se apresentar, esta nova percepção ser confrontada com a representação verbal anteriormente constituída. Neste momento é que se daria o conhecimento propriamente dito ou, se preferirmos, a percepção, no sentido humano do termo, já confrontada com a memória constituída pelas representações simbólicas.

Freud define sinteticamente as percepções como "catexias em $p$ si provenientes de phi (do mundo externo)". (Freud, 1895, p. 473) Para compreender esta definição temos que remontar aos termos da sua constituição. O Projeto para uma psicologia científica tenta explicar os fenômenos psíquicos para neurologistas dos fins do século passado, obedecendo, portanto, a um esquema cientificista bem a gosto do leitor destinatá- 
rio; e termina por construir uma complexa máquina neuronial cuja descrição antecipa os esquemas dos modernos computadores.

$\mathrm{Na}$ máquina humana estudada por Freud podemos aproximativamente definir os termos do seguinte modo: catexia é uma quantidade de energia psíquica presente nos neurônios. Os neurônios $p h i$ são permeáveis, isto é, permitem a passagem de Qs (quantidades), após o que voltam ao estado anterior, estando aptos a transmitir novas catexias. Este sistema de neurônios ( $\not h i)$ está ligado aos sentidos e conseqüentemente voltado para o mundo externo. Já os neurônios do sistema psi são impermeáveis, retêm as catexias recebidas e são os responsáveis pela memória. Podemos dizer que o sistema phi está aberto para o mundo físico, objetivo, enquanto o psi dá conta dos fatos do mundo psíquico, subjetivo.

Vejamos, então, a primeira exposição de Freud a respeito do papel da fala na função psíquica:

Além de possibilitar o (re)conhecimento, as associações verbais efetuam ainda outra coisa de suma importância. As facilitações entre os neurônios constituem, com sabemos, a memória, ou seja, a representação de todas as influências que experimentou a partir do mundo externo. [...] Mas não dispõe de nenhum meio para discernir entre esses resultados dos processos de pensamento e os resultados dos processos perceptivos. [...] As indicações de descarga verbal são, porém, as que vêm agora sanar esta lacuna; pois equiparam os processos de pensamento com os perceptivos, conferindo-lhes realidade e possibilitando a sua lembrança. (Freud, 1895, p. 480)

Quase trinta anos depois, ele volta ao mesmo tema, para confirmar as suas inferências:

O papel desempenhado pelas representações verbais se torna agora perfeitamente claro. Através de sua interposição, os processos internos de pensamento são transformados em percepções. É como uma demonstração do teorema de que todo conhecimento tem sua origem na percepção externa. Quando uma hipercatexia do processo de pensamento se efetua, os pensamentos são realmente percebidos - como se proviessem de fora - e, conseqüentemente, são considerados verdadeiros. (Freud, 1923, p. 36)

Freud trata com igual ênfase os fatos provenientes do sujeito, por um lado, e do objeto, por outro. Parte do pressuposto de que o conhecimento tem sua origem na 
percepção externa, no que está de acordo com os empiristas, mas ressalta a disposição da natureza para conferir realidade a fatos de ordem subjetiva, utilizando o apoio concreto das representações verbais.

A linguagem tem o poder de atribuir aos fatos psíquicos um estatuto de realidade comparável aos fatos externos, e como é ela mesma que processa estes fatos do mundo dos objetos para construir a realidade humana, pode ainda rejeitar o mundo dos objetos como base de apoio, em favor do mundo imaginário. Estamos, portanto, inteiramente a mercê da linguagem, posto que somos por ela falados. Heidegger não está só quando abraça a idéia de um Ser atingível apenas através da dimensão da linguagem, que não é dominada pelo homem, porque não é o homem que nela se pensa, mas ela que se pensa no homem. "A linguagem é a casa do ser. Nesta habitação do ser mora o homem. Os pensadores e os poetas são os guardas desta habitação. A guarda que exercem é o consumar a manifestação do ser, na medida em que a levam à linguagem e nela a conservam”. (Heidegger, 1979, p. 149)

Jacques Lacan, ao sublinhar o lugar da linguagem na descoberta de Freud, recorre freqüentemente à filosofia de Heidegger, promovendo a comunhão dos dois autores. "É o mundo das palavras que cria o mundo das coisas, primeiramente confundidas no bic et nunc do todo em devir, dando seu ser concreto à sua essência". (Lacan, 19, p. 141). É a título de conclusão a esta afirmativa que ele escreve: "O homem fala, mas é porque o símbolo o fez homem."

Umberto Eco examina os pontos de convergência de Lacan e Heidegger afirmando que apesar do seu nome ser muitas vezes omitido no curso dos escritos lacanianos, Heidegger aparece bem mais do que Freud como a raiz que dá origem a toda a doutrina da Ausência. E conclui que o pensamento estrutural de Lacan revelase, portanto, como um caso de maneirismo heideggeriano.

Voltando ao paralelo entre os modelos de construção da realidade pelos animais simbólicos e pelos não-simbólicos, observemos que se, por um lado, a realidade humana é mais ampla e abrangente do que a dos animais, por outro lado, é mais sujeita aos labirintos do equívoco, porque refrata, ao mesmo tempo que substitui e representa, os fatos primitivos oferecidos pela natureza.

A impossibilidade do conhecimento objetivo puro constituiu motivo de preocupação para alguns filósofos, desde os pré-socráticos até o nosso século. Heráclito, que insistia no fato da sabedoria ser alheia a todos os discursos, proclamava a ilusão dos homens quanto ao conhecimento das coisas visíveis. É célebre a sua máxima: "Natureza ama esconder-se". (Heráclito, Fragmento 117) Mas foi Bacon quem insis- 
tiu com mais veemência na questão. Considerado como o primeiro dos modernos e o último dos antigos, graças ao fato de ter sido um dos iniciadores do empirismo e da ciência moderna, proclamou o primado da natureza e, até certo ponto, desdenhou da cultura.

A tradição baconiana compreende como ciência apenas a investigação empírica, colocando sob suspeita toda especulação teórica. O próprio filósofo foi um crítico mordaz de Aristóteles, a quem considerava o pior dos sofistas, reservando para Platão os epítetos trocista, teólogo entusiasta e poeta pleno de vaidade. "A natureza supera em muito, em complexidade, os sentidos e o intelecto. Todas aquelas belas meditações e especulações humanas, todas as controvérsias são coisas malsãs. E ninguém disso se apercebe." (Bacon, Aforismo X)

Rejeitando as teorias que colocam o homem como centro catalisador, Bacon nega a asserção de que os sentidos do homem são a medida das coisas: «Muito ao contrário, todas as percepções, tanto dos sentidos como da mente, guardam analogia com a natureza humana e não com o universo. O intelecto humano é semelhante a um espelho que reflete desigualmente os raios das coisas e, dessa forma, as distorce e corrompe». (Bacon, Aforismo XLI) É evidente que na sua doutrina o papel do homem com relação ao conhecimento deve ser meramente passivo, porque a filosofia baconiana desconhece a realidade enquanto fenômeno dialético. Qualquer intervenção humana na constituição do real é considerada uma agressão à ordem natural.

Sua bem fundada teoria da obediência à natureza como forma de dominá-la termina por se converter numa nova espécie de culto panteísta, cuidadosamente disfarçado. Se por um lado, Bacon soube reconhecer o lugar da ideologia no sistema e prática da linguagem, por outra banda, foi um contrito devoto do silêncio, contra o verbo.

Vejamos ainda a palavra do filósofo:

Com efeito, os homens se associam graças ao discurso, e as palavras são cunhadas pelo vulgo. E as palavras, impostas de maneira imprópria e inepta, bloqueiam espantosamente o intelecto. Nem as definições, nem as aplicações com que os homens doutos se munem e se defendem, em certos domínios, restituem as coisas ao seu lugar. Ao contrário, as palavras forçam o intelecto e o perturbam por completo. E os homens são, assim arrastados a inúmeras e inúteis controvérsias e fantasias. (Bacon, Aforismo XIIII)

Mais adiante, no Aforismo XLIX, Bacon observa que o «intelecto humano não é luz pura, pois recebe influência da vontade e dos afetos, donde se pode gerar a 
ciência que se quer." Este pequeno trecho baconiano apresenta pela primeira vez, ao que eu saiba, o problema da ideologia nas ciências ideológicas. Ou melhor: situa as ciências como sendo essencialmente ideológicas.

Mesmo diante da perplexidade e da crítica sistemática dos adversários da cultura, em favor da natura, o homem, ao longo do seu processo civilizatório, deixa de conviver diretamente com outro animal da mesma espécie biológica, para conviver com a sua imagem cultural ou com a sua representação simbólica. Deixa de conviver com o outro para existir verdadeiramente como homem e se reconhecer através do outro.

Quando um homem conhece outro homem, compõe o seu modo de conhecer com a soma de atributos interiores e exteriores, isto é, não apenas com os valores inerentes ao indivíduo, mas com o valor simbolicamente adquirido no contexto social, isto é, com as imagens da cultura. A posição econômica, o grau de instrução, a raça, a família, o lugar onde se situa etc. são elementos significantes nos sistemas culturais. A convivência social, em cada lugar e tempo, elege um conjunto de atitudes como símbolos conscientes e inconscientes de virtudes supremas que, quanto menos conscientes, mais decisivamente atuam sobre o pensamento estabelecido.

As mais simples atitudes do homem no teatro da cultura não são casuais e desmotivadas, mas traduzem motivações inconscientes diversas.

Como então ter acesso ao outro, se entre mim e ele estão os códigos que ditam as suas ações e aqueles que ditam o modo como eu devo ler estas ações? Se a nos unir existe um traço de união, que nos separa: o lugar na cultura?

O homem é um prisioneiro da cadeia simbólica, ator que repete o roteiro da cultura. Um animal que fica cativo das teias que ele mesmo tece.

Ao abandonar o estádio natural e ingressar no simbólico ou no cultural, o homem inclui entre as suas tarefas a construção do real. Desta forma, a realidade humana se confunde com o espaço do simbólico e da cultura - o espaço de convenção -, através do trabalho e da inteligência do próprio homem.

O adágio ensina: a aranha vive do que fia. Enquanto o homem constrói teias mais poderosas, onde ele mesmo se enlaça sem saber, busca, no mundo projetado para além de si, o construtor da trama que ele mesmo tece.

Conta a lenda que dormia

Uma Princesa encantada

A quem só despertaria

Um infante que viria

De além do muro da estrada. 
E, se bem que seja obscuro

Tudo pela estrada afora,

E falso, ele vem seguro,

$E$, vencendo estrada e muro,

Chega onde em sono ela mora.

$\mathrm{E}$, inda tonto do que houvera,

À cabeça em maresia,

Ergue a mão, e encontra a hera,

$\mathrm{E}$ vê que ele mesmo era

A Princesa que dormia. (PessoA, 1972, p. 181)

O conhecido poema iniciático, ou destinado a (re) velar alguns aspectos da descoberta essencial, entre as sombras e o caminho iluminado, oferece ainda a possibilidade de uma leitura a nível da consciência e da razão cartesiana: a construção do espaço cultural pelo indivíduo enquanto condômino do contrato social. Aliás, ambas as leituras, sem se excluírem mutuamente, são complementaridades; como são faces de uma mesma moeda - o Encoberto e o Revelado.

Cidadão da cultura, do simbólico e da construção empreendida pela técnica do homem - comprometido até o desvario, como nas falas do engenheiro Álvaro de Campos -, Pessoa retorna à natureza através do discurso do mestre Caeiro. Mas seu culto à natureza não difere do conseqüente panteísmo apontado em Bacon. O filósofo Antonio Mora, habitante de arca de Pessoa que, segundo o poeta, teria morrido louco, escreve:

O fim da arte é imitar perfeitamente a Natureza. Este princípio elementar é justo, se não esquecermos que imitar a Natureza não quer dizer copiá-la, mas sim imitar os seus processos. Assim a obra de arte deve ter os característicos de um ser natural, de um animal; deve ser perfeita, como são, e cada vez mais o vemos quanto mais a ciência progride, os seres naturais; isto é, deve conter quanto seja preciso à expressão do que quer exprimir e mais nada, porque cada organismo, ou cada organismo considerado perfeito, deve ter todos os órgãos de que carece, e nenhum que lhe não seja útil. (Pessoa, 1976, p. 231)

Pessoa, pela boca deste outro Antonio, refuta a tese basilar de Platão segundo a qual a idéia de perfeição provém do ideal. De acordo com a teoria pessoana exposta 
por Antonio Mora, tal idéia nasce da contemplação das coisas, da Matéria, e da já referida perfeição que a Natureza confere àquilo que produz.

Tal concepção filia o pensamento do filósofo heterônimo à tradição que vai do realismo aristotélico ao empirismo moderno. $\mathrm{Na}$ esteira do conceito aristotélico de mímese, podemos ler, num outro manuscrito, também assinado por Antonio Mora: "Procura a arte imitar a natureza; mas imitá-la completamente. À obra de arte, porém, dado que é produto do pensamento e não da natureza, falta uma cousa - a vida." (PEssoA, 1976, p. 232) Ora, é precisamente por isso que o filósofo Mora, habitante da linguagem do poeta, vai em busca do mito de Pigmalião e Galatéia, recordando que "o grego compreendeu a dor de a arte nunca poder chegar à vida, por não poder criar a vida verdadeiramente." (Pessoa, 1976, p. 232)

Estas preocupações com a identificação dos processos construtores da realidade cultural do homem, como acréscimo ao trabalho da natureza, ocupam o projeto pessoano. Quer na poesia, quer nas inúmeras notas deixadas na famosa arca e reunidas nas publicações da sua obra em prosa, Pessoa já revelava a consciência de que a construção do real é tarefa da cultura.

\section{$\operatorname{son}$}

\section{BIBLIOGRAFIA}

AGOSTINHO, Santo (1980): Confissões [Confessionum], trad. J. Oliveira Santos \& Ambrósio de Pina. In AGOSTINHO: Confissões e De magistro. $2^{\mathrm{a}}$ ed. São Paulo, Abril Cultural.

BACON, Francis (1979): Novum organum - ou verdadeiras indicacõos acerca da interpretação da natureza [Pars secunda operis quae dicitur novum organum sive indicia vera de interpretatione naturae], trad. e notas de J. A. R de Andrade. São Paulo, Abril Cultural.

CASSIRER, Ernst (1923): La philosophie des formes symboliques. Vol. I: Le langage [Philosophie der symbolischen Formem] traduit de l'allemand par Ole Hansen-Love et Jean Lacoste. Paris, Minuit.

CASSIRER, Ernst (1925a): La philosopbie des formes symboliques. Vol. II: La pensée mytique [Philosophie der Symbolischen Formen], traduit de l'allemand par Jean Lacoste. Paris, Minuit.

CASSIRER, Ernst (1925b): Linguagem e mito [Sprache und Mythos: Ein Beitrag zum Problem der Goetternamen]; trad. J. Guinsburg \& Miriam Schnaiderman. São Paulo, Perspectiva. (Col. Debates, 50).

CASSIRER, Ernst (1933): Le langage et la construction du monde des objets, in CASSIRER et alii: Essais sur le langage. Paris, Minuit, 1969, p. 37-68 (Col. Les sens commun).

CASSIRER, Ernst (1944): Antropologia filosófica: ensaio sobre o bomem [An essay on man]; trad. Vicente Queiroz. 2a ed. São Paulo, Mestre Jou, 1977.

ECO, Umberto (1968) : A estrutura ausente: introdução à pesquisa semiológica [La struttura assente]; trad. Pérola de Carvalho. São Paulo, Perspectiva, Universidade de São Paulo, 1971, 428 p. (Col. Estudos, 6).

FERREIRA, Vergílio (1969): Mudança; romance. $3^{\text {a }}$ ed. Lisboa, Portugália. 
FREUD, Sigmund (1895): Projeto para uma psicologia cientifica [Entwurf einer Psychologie / Project for a scientific psichology]; trad. José Luis Meurer. Edição Standard Brasileira, Vol. I. Rio de Janeiro, Imago, 1977, p. 379-517.

FREUD, Sigmund (1923): O ego e o id [Das Ich und das Es / The Ego and the Id]; trad. José Otávio Abreu. Edição Standard Brasileira, Vol. XIX. Rio de Janeiro, (1976), p. 11-83.

GUERREIRO, Mário (1977): Signo sonoro \& signo musical: um esboço de psicologia fenomenológica. Ciências Humanas. Revista da Universidade Gama Filho. Rio de Janeiro, Vol. I, no 2, 1977, p. 45-57.

HEIDEGGER, Martin (1979): Sobre o humanismo. Carta a Jean Beaufret, In 3/4: Conferências e escritos filosóficos; tradução, introdução e notas de Ernildo Stein. São Paulo, Abril Cultural.

HERÁCLITO de Éfeso (1978): Fragmentos; trad. J. Cavalcante de Souza. In OS PRÉ-SOCRÁTICOS: Fragmentos, doxografia e comentários, seleção de José Cavalcante de Souza. São Paulo, Abril Cultural, p. 73136 (Os Pensadores).

HOBBES, Thomas (1640): A natureza bumana [The elements of law, natural and politic]; trad. introdução e notas de João Aloísio Lopes. Lisboa, Imprensa Nacional / Casa da Moeda, 1983 (Col. Clássicos de Filosofia).

HOBBES, Thomas (1650): Leviatã; ou Matéria, forma e poder de um estado eclesiástico e civil; trad. João P. Monteiro \& M. B. Nizza Silva. São Paulo, Abril, 1979.

LACAN, Jacques (1966): Écrits. Paris, Seuil, 928 p. (Le champ freudien).

LACAN, Jacques (1965): O mito individual do neurótico; trad. Cardoso e Cunha et alii. Lisboa, Assírio \& Alvim, 1980.

LACAN, Jacques (1978): Função e campo da fala em psicanálise. In -: Escritos [Écrits]; trad. Inês OsekiDerpé. São Paulo, Perspectiva (Col. Debates, 132).

LÉVI-STRAUSS, Claude (1949): A eficácia simbólica. In -: Antropologia estrutural [Anthropologie structurale]; trad. Chaim Katz \& Eginardo Pires. Rio de Janeiro, Tempo Brasileiro, 1970. (Biblioteca Tempo Universitário, 7).

LÉVI-STRAUSS, Claude (1955): A estrutura dos mitos. In -: Antropologia estrutural [Anthropologie structurale]; trad. Chaim Katz \& Eginardo Pires. Rio de Janeiro, Tempo Brasileiro, 1970. (Biblioteca Tempo Universitário, 7).

MARX, Karl (1956): Teses sobre Feuerbach. In -: Trechos escolbidos sobre filosofia; trad. Inácio Rangel. Rio de Janeiro, Calvino, p. 60-63.

MARX, Karl (1978): Manuscritos econômico-filosóficos e outros textos escolbidos. Seleção de José Arthur Giannotti, trad. José Carlos Brunni et alii. $2^{\mathrm{a}}$ ed. São Paulo, Abril Cultural, 410 p. (Os Pensadores).

MCLUHAN, Marshall (1964): Os meios de comunicação como extensões do homem [Understanding media: the extensions of man]; trad. Décio Pignatari. $4^{a}$ ed. São Paulo, Cultrix, 1974.

PESSOA, Fernando (1972): Obra poética; organização, introdução e notas de Ma Aliete Galhoz. Rio de Janeiro, Aguilar.

PESSOA, Fernando (1976): Obras em prosa; organização, introdução e notas de Cleonice Berardinelli. Rio de Janeiro, Nova Aguilar.

ROUSSEAU, Jean-Jacques (1962a): Do contrato social; on Princípios do direito politico [Du contrat social ou princips du droit politique]; trad. Lourdes Machado. Obras politicas. Vol. II. Porto Alegre, Globo, p. 1165.

ROUSSEAU, Jean-Jacques (1962b): Ensaio sobre a origem das línguas; no qual se fala da melodia e da imitação musical [Essai sur l'origine des langues oú il est parlé de la mélodie et de l'imitation musicale]; trad. Lourdes Machado. Obras políticas, Vol. II. Porto Alegre, Globo, p. 417-479.

SEIXAS, Cid (1984):Uma estética marxista: Della Volpe. Estudos lingüisticos e literários, n ${ }^{\circ}$. Salvador, Universidade Federal da Bahia, mai. 84, p. 93-101.

SHAFF, Adam (1974): Linguagem e conbecimento [Jezyk a Poznanie]; trad. Manuel Reis (do texto francês estabelecido por Claire Brendel. Coimbra, Almedina, $304 \mathrm{p}$. 
SHAFF, Adam (1968): A definição funcional de ideologia e o problema do 'fim do século da ideologia'. Documentos, n 2, São Paulo, p. 7-23.

SHAFF, Adam (1976): La objetividad del conocimiento a la luz de la sociologia del conocimiento y del análisis del lenguaje. In VERÓN, Eliseo (Selección): El proceso ideológico. Buenos Aires, Tiempo Contemporáneo, $3^{a}$ ed., 1976, p. 47-79 (Col. Ciencias Sociales).

UEXKÜLL, Johannes von (1909): Umwelt und Innenwelt der Tiere / Teoretische Biologie, Berlim, 1938.

Cid Seixas Fraga Filho é Professor Titular da Universidade Federal da Bahia e docente fundador do Programa de Pós-Graduação em Literatura e Diversidade Cultural da UEFS. Graduado pela Universidade Católica de Salvador, Mestre pela UFBA e Doutor pela USP. Jornalista, poeta e crítico literário. Publicou, dentre outros livros, Triste Bahia, ob! quão dessemelhante (1996), O lugar da linguagem na teoria freudiana (1998), e O trovadorismo galaico-português (2000). É editor de Légua \& meia. 